\title{
Variants of knowledge control in the distance learning system of a university
}

\author{
N.A. Gluzman ${ }^{1 *}$, N.T. Kolesnik ${ }^{2}$, and O.I. $\mathrm{Mysin}^{3}$ \\ ${ }^{1}$ V.I. Vernadsky Crimean Federal University, Simferopol, Russia \\ ${ }^{2}$ State Educational Institution of Higher Education of the Moscow Region Moscow Region State \\ University, Mytishchi, Russia \\ ${ }^{3}$ State Educational Institution of Higher Education of the Moscow Region Moscow Region State \\ University, Mytishchi, Russia
}

\begin{abstract}
The article is devoted to the study of the distance learning system in the context of a modern university, aimed at the formation of a highly qualified personnel potential of the country. Particular attention is paid to consideration of the essence and specifics of distance learning, its separately taken technologies and resources. The system of monitoring the students' knowledge has become the key object of the study, in the context of remote supplying the specialists of different levels and directions with professional training. The role of distance technologies in the process of regular quality control of students' knowledge is comprehended and actualized, the main theses regarding the variants of control are revealed. The questionnaire method was defined as the main method of research, which was carried out in the conditions of the leading university of the Republic of Crimea - V.I. Vernadsky Crimean Federal University. The subject of the questionnaire was to identify the role of distance technologies in the knowledge control system, as well as to determine the most effective options for such control in a modern university. The respondents were the teaching staff of the University of various areas of training, degrees, forms and levels of education. The results of the study can be found in the final part of it.
\end{abstract}

\section{A problem statement}

The development of the educational industry and its individual elements - technologies, methods, approaches, etc. - led to the inevitable involvement of the system of distance technologies in the organization of the educational process. Today they are not considered outlandish and are actively used in teaching practice. Education has become more accessible, modernized, more informed, more relevant and more intensive. In this regard, the key problem of the organizational and administrative pedagogical activity of the modern pedagogical community arose - the implementation of high-quality and multi-level control of students' knowledge through the application of new forms and methods. At the same time, it is important to determine and select such means that could fully comply with

*Corresponding author: ipcs-profped@yandex.ru 
the currently existing criteria for the quality of education not only in a particular educational institution, but in the entire educational environment of the state as a whole.

The research problem is based on the fact that, as you know, knowledge control is a key method for identifying student's problems of an educational nature, as well as a method for assessing his level of knowledge, which will make it possible to adjust the educational route in accordance with which the professional training of a future specialist is carried out. The methods of such control can be objectively evaluated especially in terms of its inclusion into the process of distance learning, which occupies a separate educational field and is the leading one today. Moreover, it is important that distance education, which in many respects competes with traditional education, adopts not only some vectors in accordance to which specialists are trained, but some problems as well. Thus, it turns out that the problem of organizing an effective system for students' knowledge monitoring in universities originates in traditional education and smoothly flows into distance learning, becoming a certain feature of it.

\subsection{The objective of the work}

The described above problem is reflected in the works of many Russian researchers, including L.I. Ayupova, S.A. Vorobieva, O. V. Grigorash, O. Yu. Zaslavskaya, V.P. Zinchenko, E.V. Kirsanov, V.I. Chernenko, I. V. Kiyan, N.V. Lomovtseva, E.S. Polat, M.V. Moiseeva, A.E. Petrov, P.L. Pekker, A.V. Khutorskoy and others. Their researches form the basis of the theoretical part of this work and represent a significant potential that allows us to base our own judgments and analytical actions on the already existing, developed principles. The works of the above-mentioned researchers have formed a complete picture that exists in distance education today, and outlined the range of theoretical key components required for further research on this topic. Many of them are cited and mentioned by us consciously in the subsequent parts of the article.

This study continues the work on the previously identified problems and their separate segments and also presents a new look at their solution. It is important to note that it is based on a survey of the teaching staff of V. I. Vernadsky Crimean Federal University which gives a new understanding of the problem and highlights aspects previously not considered by other scientists. The latest works of many of the above-mentioned scientists are based on the description and assessment of the problem of students' knowledge monitoring, at the same time, statistical data are rarely cited, which, in our opinion, requires a practical element - confirmation of the relevance of a theoretical study.

\section{Materials and the results of the research}

The purpose of the study is to compare the technologies used in one of the leading higher educational institutions of the Republic of Crimea for monitoring students' knowledge in conditions of distance learning. In addition, the study aims to accomplish a number of related objectives:

- identification of problems existing nowadays in the monitoring system;

- determination of the most effective options for controlling the knowledge of future specialists in the context of distance learning;

- conducting analytical research and comparison between the experience of various scientists engaged in the research of this topic.

The achievement of the goal and objectives of the research will allow us to actualize the above mentioned problem and to bring it to a new level of pedagogical comprehension. This will make it possible to make every effort and to reveal the maximum pedagogical 
potential, to find new resources for solving problems related to distance learning and digital pedagogy.

The distance learning is a special form of education, which in most cases provides the territorial detachment of a student and a teacher-tutor. Thanks to its means, the fastest possible transmission, storage and transformation of information is possible. Such training in comparison with the traditional one has either advantages and disadvantages, at the same time, however, it adopts the problems formed in the conditions of organizing classical educational activities.

Teaching carried out by means of distance learning technologies sufficiently intensifies the process of acquiring professional competence. In this regard, modern universities face new challenges in finding the best options for knowledge control, which will allow graduates to meet the competitive environment and the modern labor market in future [10].

O.Yu. Zaslavskaya and M.A. Sergeeva point to the fact that the knowledge control in the distance learning system of the university, its means and results clearly reflect the effectiveness of all elements of education:

- teachers, their compliance with the criteria and specialization of the educational institution;

- pedagogical technologies that are aimed at implementing the goals and objectives set during the planning and preparation of the educational space;

- consequently, goals and objectives that are priorities in the conditions of the distance learning system of the educational institution;

- means, methods and forms of educational activity, its control, which allow not only to carry out the organizational and administrative pedagogical activity, but also to achieve certain educational results;

- professional communities intended to optimize available opportunities, etc. [6].

The above-mentioned elements illustrate especially clearly the need for regular monitoring activities that can minimize learning risks and problems. At the same time, control should touch upon all the elements of the educational process, all its levels and stages, as well as all subjects and their activities. Based on this, we can conclude that pedagogical workers need to have a whole range of ways of carrying out the regular and timely monitoring, and learners - ways of self-controlling, which is just as important as an external control. This is complicated by the very form of distance learning due to the remoteness in space and the teacher's uncertainty about the fairness and objectivity of assessment by means of distance technologies.

N.V. Lomovtseva believes that this is also due to insufficient pedagogical awareness in the system of distance learning principles, which in their turn underlie all the activities of a digital (distance) teacher. The researcher refers to such principles:

- the principle of objectivity, which provides for an objective comprehensive assessment of the educational cognitive activity of students in the context of distance learning. In this case, the subjective factor should be minimal or completely absent, since it can significantly violate the analytical integrity;

- the principle of democracy, which consists in the formation of a field with equal conditions for all students, as well as with equal conditions for the assessment and control of educational activities;

- the principle of mass character and short duration, which consists in the fact that control in the distance learning system of a university should be organized and managed in such a way that as many students as possible will be evaluated and tested in the shortest time period [10].

These principles guarantee the effectiveness of educational activities in the distance learning system only in the case of pedagogical competence in this matter, as well as in the case of regular updating of the material, technical, methodological and methodological 
bases of the educational institution that provides professional training of specialists. In our opinion, they are especially important for this study, since they allow us to identify the specifics of both distance learning and options for knowledge control in its conditions [10; $11]$.

So, having considered the key characteristics that allow us to draw conclusions about the specifics of knowledge control in the distance learning system of a modern university, it seems to us the most logical to consider various options for this very control, and after that, we will confirm the effectiveness of each of them through the results of a survey of pedagogical personnel of V. I. Vernadsky Crimean Federal University.

I.V. Kiyan believes that there are various methods of control that modern teachers should pay particular attention to. She identifies such basic control methods as testing (through the software of classes), self-control of students' own activities, term papers and theses [9].

Testing with the involvement of special software allows not only to control the performance of certain test tasks by students, but also does not require any additional resources from the teacher, since they are all in the software. The thing is that students cannot move on to the next task without completing the previous one, that allows the teacher to keep an eye on which issues are slowing down and also to draw a conclusion regarding the degree and level of assimilation of the material by the students. Thus, the teacher controls the student's knowledge, pointing out his gaps through the analysis of test results provided by the software.

Independent activity and self-control by a student are not widely spread among modern teachers, but it is often quite an effective and intensive way of controlling knowledge. It is important to understand that a student who is interested in obtaining qualifications and the necessary knowledge is guided by his own motivation and being an independent adult strives for self-control. In this regard, a number of problems are formed related to the development of positive motivation of students [1].

The implementation and presentation of term papers (and subsequently theses) is an effective form of control in both traditional and distance education. They are extremely effective when a student studies a module or a course of a curriculum systematically and consistently and are aimed at presenting the student's practical skills acquired in the process of professional training. Distance technologies here allow to control the process of creating a term paper, since it is convenient for a teacher to get acquainted with the content of the work online, to respond to problems immediately and also to provide timely support [9].

Other researchers identify a more extended range of options for the knowledge control in the distance learning system of a university $[2 ; 3 ; 4 ; 5 ; 10 ; 13]$. It was it that we focused on when conducting a questionnaire to identify the effectiveness of certain forms of monitoring students' knowledge, since it represents the most complete and appropriate list of variants, and also includes in its structure both special and general forms of control (that is, inherent in both distance learning and traditional learning systems). Further let us consider each of these types and compare them with the results of the survey, which are presented in the table below (Table 1).

In accordance with the above-mentioned results, obtained during a survey of teachers (about 150 respondents) of V.I. Vernadsky Crimean Federal University, one can come to certain conclusions regarding the distance technologies used in the university. Let's consider each of the presented options for monitoring students' knowledge. 
Table 1. Evaluation of the effectiveness of various methods of monitoring students' knowledge in the context of distance education at a university (\%).

\begin{tabular}{|l|l|l|l|l|}
\hline & $\begin{array}{c}\text { Absolutely } \\
\text { ineffective }\end{array}$ & $\begin{array}{c}\text { Rather } \\
\text { ineffective } \\
\text { than effective }\end{array}$ & $\begin{array}{c}\text { Rather } \\
\text { effective than } \\
\text { ineffective }\end{array}$ & $\begin{array}{c}\text { Absolutely } \\
\text { effective }\end{array}$ \\
\hline Written reports & $\mathbf{8 1 , 7}$ & 6,3 & 6,3 & 5,7 \\
\hline Remote teleconferences & 1 & 15,2 & $\mathbf{6 3 , 5}$ & 20,3 \\
\hline Making individual projects & 12,9 & 16,3 & 24,5 & $\mathbf{4 6 , 3}$ \\
\hline Making group projects sharing & 12,2 & 18,3 & $\mathbf{3 7 , 6}$ & 31,9 \\
\hline $\begin{array}{l}\text { Testing (with screen } \\
\text { function) }\end{array}$ & 6,6 & 14,2 & 19,4 & $\mathbf{5 9 , 8}$ \\
\hline Testing (using special software) & 7,1 & 6,5 & 28,3 & $\mathbf{4 1 , 9}$ \\
\hline Written surveys via social media & $\mathbf{6 7 , 1}$ & 16,9 & 12,3 & 3,7 \\
\hline $\begin{array}{l}\text { Self-control by students of their } \\
\text { own activities }\end{array}$ & 21,9 & $\mathbf{3 9 , 8}$ & 15,7 & 22,6 \\
\hline
\end{tabular}

$88 \%$ of practicing educators found written reports extremely ineffective as a form of knowledge control. The point is that the key aspect here is a written research based on the received knowledge, which is based on the curriculum. This program had been previously presented to other students, and therefore - was reviewed in previous studies, which allows students to plagiarize and base their own research on the already existing scientific data [14]. The teachers of the Crimean university drew attention to the high percentage (on average $50-60 \%$ ) of plagiarism, which indicates the low efficiency of the method of written reports.

Conducting remote teleconferences, on the other hand, was identified by teachers as one of the most effective control options $-83.8 \%$ of respondents considered this variant to be acceptable. Teleconferences in general are the most important part of the modern educational process in the distance learning system. They suppose the student's credit work to be done orally (as a rule), in a group or in individual form. At the same time such conferences allow teachers to assess the depth and degree of students' involvement in the curriculum, as well as to ask control questions spontaneously, thereby forcing students to respond to them in the most mobile and quick manner [10].

Making individual projects is considered to be one of the most effective ways of involving students in independent activities, as well as an important element in activation of their creativity. $70.8 \%$ of teachers confirmed this thesis and considered it to be extremely important today not only for the process of obtaining qualifications, but also for the direct professional activities of students in future. Making projects allows to check the student's abilities and skills, to assess the degree of his understanding and awareness of his role in the system of professional relations [11]. "Students of V.I. Vernadsky Crimean Federal University regularly present the results of making individual projects at various federal and international competitions, which testifies to the high project culture of the university and teachers, and also takes a special place in the distance learning system", according to teachers. At the same time making group projects according to the same teacherrespondents, is also an effective, although slightly less than individual, option for knowledge control in the system of higher distance learning. This is evidenced by the indicators from the above-mentioned table $-69.5 \%$ of respondents agree with this opinion.

The process of testing has always occupied a special niche in the complex of monitoring students' knowledge both in the traditional and distance learning systems. It is objective, democratic, massive and economical in time, which fully corresponds to the above principles of distance learning, as evidenced by many researchers $[3 ; 4 ; 7 ; 10]$. Despite this, the indicator of the effectiveness of testing with the use of screen sharing technology, based on the respondents' answers, is quite low in comparison with the above options and is only 
$58.8 \%$, that is $41.2 \%$ of teachers consider such testing to be ineffective. In our opinion, it is due not so much to actual inefficiency as to the human factor: students turn on a special program on the computer that transmits the image of its screen to the teacher who monitors all their actions. Because of this, students often feel constrained, and teachers psychologically uncomfortable [10].

Testing with the help of special software was found to be effective by $70.2 \%$ of teachers, taking the questionnaire, and was considered more effective, since it does not require the teacher's "personal" presence. He just needs to check the answers and delays that arose when passing the test, immediately after passing it to assess the student's knowledge. This technology is extremely widespread today and is the leading one in the knowledge assessment and control system [8].

The most ineffective variants became: written surveys carried out through social networks $-84 \%$; technology of students' self-control of their own activities and knowledge $-61.7 \%$. As you know, social networks today occupy a special place in the life of every modern person. Their use in the distance learning system is quite natural. In this regard, leading educational specialists suggested that social networks can significantly increase attention and stimulate students' interest in learning activities [12]. However, the interviewed teachers did not confirm this idea and expressed dissatisfaction with this variant. This is due to the fact that written answers to the given questions are often plagiarized and based not on their own knowledge, but on Internet resources. Teachers consider it to be the main problem with this form of control. The same applies to the technology of self-control $-61.7 \%$ of modern teachers agreed that the degree of awareness of modern students is quite low and does not represent the necessary basis for the development of their self-study skills. In addition, it is difficult for a teacher to assess the student's knowledge, as well as to control it.

Based on what had been said, we can conclude that remote teleconferences, making projects (both individual and group) and testing were recognized as the most effective options for knowledge control in the distance learning system in a modern university. This is due to their relative "easiness" of organization, as well as the saving of time for both the teacher and the student.

The monitoring of the educational activities of modern students and graduates of the university, striving for professionalism, is the most important element of the distance education process, since it allows to influence on the process of managing of the cognitive activity of students actively [10]. It allows learning to achieve maximum outcomes:

- $\quad$ to form a clearly structured system of knowledge, skills and abilities;

- $\quad$ to recognize the gaps existing in this system and the most unexplored aspects in time;

to focus the student's attention on the quality of his own educational (and subsequently professional) activities;

- $\quad$ to help the teacher in a timely and most expedient way to assess the capabilities of students, to identify the effect of distance learning and to adjust the educational route, if necessary, etc. [7].

The knowledge control in the distance learning system by means of distance technologies was recognized as extremely effective by $89.6 \%$ of all the surveyed respondents, that confirms all that is said above. This indicates that modern teachers are guided rather by innovations and modern technologies than by traditional methods and methods of assessing and controlling knowledge, which corresponds to the main goals of education modernization [6].

Besides, many modern educators believe that distance learning assessment should be carried out not so much by teachers as by means of special computer programs. It was stated by $57.2 \%$ of respondents. At the same time, the remaining $42.8 \%$ preferred direct 
pedagogical influence even in conditions of remote education. The teachers of the so-called "old school" pursue the goal of "humanizing" of all relationships with students, especially in the context of distance learning, because in their opinion, it forms an important communicative and social experience for students, which they need in their future life [12; 14]. The younger representatives of the pedagogical community, on the contrary, recognize a certain potential of computer programs that save the teacher's time and allow him to focus on the quality of the material provided to him [10]. Such technology is able to identify gaps in the student's knowledge accurately and objectively, as well as to react instantly and to record all his delays and missing assignments.

\section{Conclusions}

Based on the results of the survey and this study, it can be concluded that the control of knowledge in the distance learning system is one of the most complex and multi-level structures, which underlies the harmonious and effective development of not only the professional culture of the student, but also of the teacher. Besides, the development of distance technologies allows modern teachers to assess students' knowledge regularly, to track their progress and regression, as well as to monitor the process of completing tasks. Thus, the educational space of the university, the distance learning system, and the system of pedagogical influence on students are being transformed.

The above-mentioned variants for knowledge control in the distance learning system of a modern university provide significant support to teachers in the process of obtaining the necessary information that underlies the further optimal formation of an algorithm for improving the quality of education. They allow us to emphasize the pedagogical influence on increasing attention and activating the mental cognitive processes of students, to take into account the specifics of the modern digital space. Based on the data obtained, we can say that they have a certain potential, which can serve as a basis or supplement for further research on the topic, as well as the basis for the further development of the field of student knowledge control in the distance learning system of a modern university.

\section{References}

1. L.I. Ayupova, Distance learning and Russian realities, Educational bulletin "Consciousness", 18, 10-15 (2016)

2. S.A. Vorobieva, Distance learning: today and tomorrow, Municipal education: innovation and experiment, 6, 64-48 (2012)

3. O.V. Grigorash, Improving the efficiency of quality management of the educational process, Higher education in Russia, 1, 72-78 (2013)

4. O.V. Grigorash, On improving the system of training university graduates, Polythematic network electronic scientific journal of the Kuban State Agrarian University, 9, 1624-1637 (2013)

5. O.V. Grigorash, Distance learning in the higher education system: advantages, disadvantages and prospects, Scientific journal of KubSAU, 101, 2048-2059 (2014)

6. O.Yu. Zaslavskaya, M.A. Sergeeva, Information technologies in the management of an educational institution, p. 128 (Moscow, 2006)

7. V.P. Zinchenko, Distance education: to the problem statement, Pedagogy, 2, 23-34 (2010) 
8. E.V. Kirsanova, V.I. Chernenko, On the issue of distance education, Bulletin of the Association of Tourism and Service Universities, 3, 78-83 (2012)

9. I.V. Kiyan, The variants of knowledge control in the distance learning system, Siberian Pedagogical Journal, 12, 52-58 (2010)

10. N.V. Lomovtseva, Control of educational activities in distance learning, Economics of Education, 2, 93-94 (2009)

11. T.N. Andryukhina, Distance learning at a university, Bulletin of the Samara state technical University. Series: Psychological and pedagogical Sciences, 2, 6-10 (2015)

12. P.L. Pekker, Distance learning: the experience of Moscow universities, Man and Education, 2 (43) 66-72 (2015)

13. E.S. Polat, M.V., Moiseeva, A.E. Petrov, Distance learning, p. 192 (Moscow: VLADOS, 1998)

14. A.V. Khutorskoy, Distance learning and its technologies, Computerra, 36, 26-30 (2002) 